\title{
PENGHITUNGAN UNIT COST PELAYANAN OPERASI SECTIO CAESAREA DENGAN METODE $A C T I V I T Y$ BASED COSTING DI INSTALASI KAMAR OPERASI RSU X SURABAYA
}

\author{
COUNTING UNIT COST OF SERVICES OPERATING SECTIO CAESAREA WITH \\ ACTIVITY BASED COSTING METHOD IN INSTALLATION OF OPERATING ROOM RSU \\ X SURABAYA \\ Nurul Ayuningtyas \\ Fakultas Kesehatan Masyarakat, Universitas Airlangga Surabaya \\ tyas.am10@gmail.com
}

\begin{abstract}
Operating room is a profit center for the hospital revenue, but also required a significant operational cost for producing activities in the operating room. Therefore, the cost control activities on operating room must be done correctly. Activity-based costing is one method used in analyzing the value of the unit cost. An analysis by appropriate methods to determine the value of the unit cost can be used as the basis for accurate pricing. The purpose of this study is to analyze the unit cost of Sectio Caesarea by Activity Based Costing in operating room at Public Hospital X Surabaya. Data were collected by observation, interview, and literature study. Results from this study is the value of the unit cost for sectio caesarea is Rp 3,336,566, - (three million three hundred and thirty-six thousand five hundred and sixty-six rupiah).
\end{abstract}

Keywords: Operating Room, Unit Cost, Activity Based Costing 


\begin{abstract}
ABSTRAK
Layanan kamar operasi merupakan salah satu profit center yang memiliki daya ungkit tinggi bagi pendapatan rumah sakit, namun dalam penyediaan jasa operasi juga membutuhkan biaya operasional yang besar pula. Oleh karena itu diperlukan kegiatan pengendalian biaya atas layanan kamar operasi yang dilakukan secara tepat. Activity based costing merupakan salah satu metode yang digunakan dalam menganalisis nilai unit cost. Sebuah analisis dengan metode yang tepat untuk menentukan nilai unit cost dapat digunakan sebagai dasar penentuan harga yang akurat. Tujuan dari penelitian ini adalah untuk menganalisis unit cost pelayanan operasi Sectio Caesarea dengan metode Activity Based Costing di instalasi kamar operasi Rumah Sakit Umum X Surabaya. Metode pengumpulan data dalam penelitian ini adalah observasi, wawancara, dan studi kepustakaan. Hasil dari penelitian ini didapatkan nilai unit cost untuk jasa pelayanan operasi sectio caesarea adalah sebesar Rp 3,336,566,- (tiga juta tiga ratus tiga puluh enam ribu lima ratus enam puluh enam rupiah).

\section{Kata Kunci : Kamar Operasi, Unit Cost, Activity Based Costing}

\section{PENDAHULUAN}

Layanan kamar operasi merupakan salah satu profit center yang memiliki daya ungkit tinggi bagi pendapatan rumah sakit. Namun,dalam penyediaan layanan di kamar operasi juga membutuhkan dana investasi yang tinggi. Kamar operasi membutuhkan teknologi medis yang canggih, sumber daya manusia dengan pendidikan khusus, serta fasilitas penunjang yang lengkap dan memadai. Tingginya investasi akan membuat biaya operasional yang harus dikeluarkan rumah sakit menjadi tinggi pula dan akan berpengaruh terhadap biaya yang harus dibayarkan oleh pengguna jasa pelayanan kamar operasi (Ratmaya, 2012).

Rumah sakit sebagai penyedia jasa pelayanan di bidang kesehatan memiliki beban tersendiri dalam memberikan mutu pelayanan yang terbaik dengan tarif atau harga yang sesuai. Besar tarif dapat ditentukan dari penghitungan nilai unit cost (biaya satuan) jasa pelayanan yang ditawarkan. Penetapan tarif atau harga merupakan suatu keputusan yang sangat penting karena dapat mempengaruhi profitabilitas dan brand image rumah sakit. Tarif juga menjadi salah satu faktor penentu bagi konsumen dalam memilih rumah sakit.

Penghitungan nilai unit cost termasuk dalam kegiatan manajemen pengendalian biaya. Kegiatan pengendalian biaya atas layanan kamar operasi harus dilakukan oleh pihak rumah sakit melalui sistem pembiayaan yang tepat, khususnya dalam memilih metode penghitungan penentuan biaya guna menghasilkan informasi biaya yang akurat (Sumilat, 2013).

Sebuah rumah sakit dituntut untuk dapat berkompetisi dalam segala bidang, baik dalam memberikan pelayanan yang semakin prima maupun berkompetisi dalam harga. Harga yang kompetitif adalah harga yang diperhitungkan secara cermat dengan memperhatikan semua faktor yang mempengaruhi terbentuknya harga meliputi biaya investasi, biaya operasional, biaya pemeliharaan dimana akan menghasilkan total biaya.

Oleh karena itu, diperlukan sebuah analisis biaya dengan metode yang tepat untuk menentukan nilai unit cost yang digunakan sebagai dasar penentuan harga. Salah satu metode yang dapat diguanakan sebagai dasar penghitungan unit cost adalah metode Activity Based Costing.

Salah satu rumah sakit umum di Surabaya (Rumah Sakit Umum X) memiliki instalasi kamar operasi yang sejak tahun 2011 mengalami penurunan jumlah pasien pengguna layanan kamar operasi. Berdasarkan data diketahui bahwa jumlah pasien pengguna layanan kamar operasi mengalami penurunan setiap tahun, dimana penurunan tersebut akan berdampak pada pendapatan dan pembiayaan operasional rumah sakit untuk 
penyelenggaraan pelayanan kesehatan.

Terjadi penurunan pendapatan dan peningkatan total biaya operasional, dapat diartikan bahwa Rumah Sakit Umum X Surabaya mengalami defisit pendapatan setiap tahunnya. Rata-rata defisit pendapatan pada kamar operasi di Rumah Sakit Umum X pada tahun 2011 sampai 2014 adalah sebesar 42,53\%. Penurunan pendapatan terbesar adalah pada tahun 2014, yakni sebesar 46,60\%.

Tujuan dalam penelitian ini adalah untuk menganalisis unit cost pelayanan operasi Sectio Caesarea dengan metode Activity Based Costing di instalasi kamar operasi Rumah Sakit Umum X Surabaya

\section{METODE PENELITIAN}

Penelitian ini tergolong penelitian deskriptif dimana dalam pengumpulan data atau informasi dilakukan tanpa adanya perlakuan sama sekali pada populasi, dengan desain penelitian cross sectional dimana data dikumpulkan pada satu waktu tertentu yang selanjutnya dilakukan analisis berdasarkan metode activity based costing.

\section{HASIL PENELITIAN}

Kegiatan penghitungan unit cost pelayanan di instalasi kamar operasi RSU X Surabaya dimulai dengan pengambilan data di instalasi kamar operasi yang kemudian digunakan sebagai bahan identifikasi. Pada kegiatan pengambilan data disepakati beberapa hal antara lain jenis data yang perlu diidentifikasi dan aktivitas penunjang. Setelah pengidentifikasian data, selanjutnya data akan dihitung nilai unit cost-nya. Tahap penghitungan unit cost adalah sebagai berikut :

1. Pengumpulan data di unit kerja pelayanan. Data tersebut meliputi:

a. Data aktivitas untuk setiap produk layanan

b. Data biaya langsung dan tidak langsung untuk setiap produk layanan meliputi bahan habis pakai medis dan non medis, gaji pegawai, peralatan medis dan non medis, gedung, pemeliharaan, dan biaya operasional lainnya.

c. Pembebanan biaya tidak langsung berdasarkan aktivitas.

2. Menghitung unit cost (biaya satuan) untuk produk layanan di instalasi kamar operasi.

Hasil pengumpulan data penghitungan unit cost di instalasi kamar operasi RSU X Surabaya, berdasarkan tahapan penghitunganya dapat dijelaskan sebagai berikut.

\section{Data Aktivitas Produksi}

Tabel berikut menggambarkan rincian tindakan atau aktivitas dan waktu yang diperlukan untuk penyedian produk layanan operasi section caesarea di instalasi kamar operasi. 
Tabel 1 Aktivitas Produksi Pelayanan Operasi Sectio Caesarea di Instalasi Kamar Operasi RSU X Surabaya

\begin{tabular}{|c|c|c|c|c|}
\hline Aktivitas & Rincian Aktivitas & $\begin{array}{l}\text { Kategori } \\
\text { Aktivitas }\end{array}$ & $\begin{array}{l}\text { Waktu } \\
\text { (Menit) }\end{array}$ & $\begin{array}{c}\text { Total } \\
\text { Waktu } \\
\text { Primer }\end{array}$ \\
\hline \multirow{5}{*}{ Persiapan } & Pendaftaran Operasi & Sekunder & 5 & \multirow{10}{*}{11} \\
\hline & $\begin{array}{l}\text { Pencatatan jadawal } \\
\text { operasi }\end{array}$ & Sekunder & 5 & \\
\hline & $\begin{array}{l}\text { Konfirmasi ke dokter } \\
\text { konsultan }\end{array}$ & Sekunder & 10 & \\
\hline & Konfirmasi ke tim bedah & Sekunder & 10 & \\
\hline & Persiapan sarana dan obat & Sekunder & 15 & \\
\hline \multirow{5}{*}{ Pre-operatif } & Serah terima pasien & Primer & 3 & \\
\hline & $\begin{array}{l}\text { Cek kelangkapan } \\
\text { adminstrasi }\end{array}$ & Sekunder & 3 & \\
\hline & $\begin{array}{l}\text { Pemberian tanda daerah } \\
\text { operasi }\end{array}$ & Primer & 5 & \\
\hline & $\begin{array}{l}\text { Menyiapkan kamar } \\
\text { operasi }\end{array}$ & Sekunder & 10 & \\
\hline & $\begin{array}{l}\text { Mengirim ke kamar } \\
\text { operasi }\end{array}$ & Primer & 3 & \\
\hline \multirow{8}{*}{$\begin{array}{l}\text { Intra- } \\
\text { operatif }\end{array}$} & Preoperative time out & Primer & 5 & \multirow{8}{*}{75} \\
\hline & Anasthesia Procedur & Primer & 5 & \\
\hline & Positioning & Primer & 5 & \\
\hline & Operating procedure & Primer & 45 & \\
\hline & Durante Operatif time out & Primer & 10 & \\
\hline & $\begin{array}{l}\text { Pencatatan kebutuhan } \\
\text { barang yang digunakan }\end{array}$ & Sekunder & 5 & \\
\hline & Penutupan luka & Primer & 5 & \\
\hline & Kelengkapan admistrasi & Sekunder & 10 & \\
\hline Post-operatif & observasi post operasi & Primer & 120 & 120 \\
\hline Pembersihan & $\begin{array}{l}\text { Pembersihan alat dan } \\
\text { ruangan }\end{array}$ & Sekunder & 30 & \\
\hline \multicolumn{2}{|c|}{ TOTAL WAKTU PRIMER } & & & 206 \\
\hline
\end{tabular}

Dari tabel 1 didapatkan data bahwa total waktu yang dibutuhkan untuk satu pelayanan operasi adalah 309 menit. Sedangkan waktu untuk melakukan aktifitas primer dalam proses pelayanan operasi di instalasi kamar operasi adalah 206 menit.

\section{Total Biaya Langsung}

Biaya yang dianalisis meliputi biaya langsung dan biaya tidak langsung. Biaya langsung terdiri dari biaya bahan habis pakai, biaya pegawai dan biaya peralatan yang berhubungan langsung dengan proses produksi satu pelayanan.

Tabel 2 Biaya Bahan Pakai untuk Pelayanan Operasi Sectio Caesarea di Instalasi Kamar Operasi RSU X Surabaya

\begin{tabular}{llc}
\hline No & $\begin{array}{c}\text { Nama } \\
\text { Bahan }\end{array}$ & $\begin{array}{c}\text { Harga } \\
\text { (Rupia } \\
\text { h) }\end{array}$ \\
\hline $\mathbf{1}$ & Obat & 139,103 \\
$\mathbf{2}$ & Injeksi & 180,140 \\
$\mathbf{3}$ & Handscon & 50,100 \\
$\mathbf{4}$ & Spuit & 17,200 \\
$\mathbf{5}$ & Jarum & 1,200 \\
$\mathbf{6}$ & Urine Bag & 4,000 \\
$\mathbf{7}$ & Chateter & 10,500 \\
\hline Total & 402,243 \\
\hline
\end{tabular}

Dari tabel 2 didapatkan informasi bahwa biaya bahan yang dibutuhkan untuk layanan operasi sectio caesarea adalah sebesar Rp. 402.243,- (empat ratus dua ribu dua ratus empat puluh tiga rupiah).

Tabel 3 menggambarkan biaya pegawai yang dibutuhkan dalam produksi layanan operasi sectio caesarea. 
Biaya pegawai yang dibutuhkan untuk menghasilkan satu layanan operasi sectio caesarea dalam satu tahun adalah sebesar Rp. 1.575.324.000,- (satu milyar lima ratus tujuh puluh lima juta tiga ratus dua puluh empat ribu rupiah). Total pelayanan sectio caesarea dalam satu tahun sebanyak 1489 pelayanan, sehingga waktu pelayanan yang dibutuhkan selama satu tahun adalah 306.734 menit. Dari penghitungan tersebut didapatkan biaya pegawai per menit dalam menghasilakn satu layanan operasi sectio caesarea adalah sebesar Rp. 5.136 (lima ribu seratus tiga puluh enam rupiah). Kemudian, biaya per menit dikalikan total waktu primer penyediaan layanan operasi sectio caesarea, sehingga didapatkan total biaya pegawai yang dibutuhkan untuk satu layanan adalah sebesar Rp. 1.057.975 (satu juta lima puluh tujuh ribu sembilan ratus tujuh puluh lima rupiah).

Tabel 3 Biaya Pegawai Pelaksanan Layanan Operasi Sectio Caesarea di Instalasi Kamar Operasi RSU X Surabaya

\begin{tabular}{|c|c|c|c|}
\hline No. & Pegawai & $\begin{array}{l}\text { Jumlah } \\
\text { Pegawai }\end{array}$ & $\begin{array}{c}\text { Total Honor Pegawai } \\
\text { dalam Satu Tahun }\end{array}$ \\
\hline 1 & Operator & 3 & Rp $169,596,000$ \\
\hline 2 & Dokter Anastesi & 2 & $\operatorname{Rp} 161,400,000$ \\
\hline 3 & Dokter Konsultan & 1 & $\mathrm{Rp} \quad 84,000,000$ \\
\hline 4 & Bidan & 12 & $\operatorname{Rp} 738,000,000$ \\
\hline 5 & Penata Anastesi & 3 & Rp $185,400,000$ \\
\hline 6 & Perawat & 3 & Rp 180,396,000 \\
\hline 7 & On loop & 1 & Rp $56,532,000$ \\
\hline \multicolumn{3}{|c|}{ TOTAL } & $1,575,324,000$ \\
\hline
\end{tabular}

Proses layanan operasi sectio caesarea memerlukan peralatan yang harus memenuhi standart yang telah ditetapkan. Dari penghitungan total biaya investasi peralatan medis di instalasi kamar operasi didapatkan total sebesar Rp 204.829.738,(dua ratus empat juta delapan ratus dua puluh sembilan ribu tujuh ratus tiga puluh delapan rupiah). Peralatan medis digunakan untuk semua pelayanan pada instalasi kamar operasi, sehingga penghitungan menit menggunakan hitung jumlah menit kerja alat dalam satu tahun, yaitu 525.600 menit. Biaya langsung peralatan medis per menit adalah sebesar Rp. 390,- (tiga ratus sembilan puluh rupiah). Dari penghitungan waktu primer dikalikan dengan biaya peralatan medis per menit, maka dapat diketahui biaya peralatan yang dibutuhkan untuk menghasilkan satu layanan operasi sectio caesarea keseluruhan adalah sebesar Rp. 80.280 (delapan puluh ribu dua ratus delapan puluh rupiah).

Total biaya langsung yang digunakan untuk satu pelayanan section caesarea adalah sebagai berikut.
Tabel 4 Total Biaya Langsung Layanan Operasi Sectio Caesarea di Instalasi Kamar Operasi RSU X Surabaya

\begin{tabular}{ccc}
\hline No. & $\begin{array}{c}\text { Rincian Biaya } \\
\text { Langsung }\end{array}$ & Biaya Langsung \\
\hline 1. & Bahan Habis Pakai & \multicolumn{2}{c}{ Rp. 402.243} \\
2. & Biaya Pegawai & \multicolumn{2}{c}{ Rp. 1.057 .975} \\
3. & Biaya Peralatan & \multicolumn{2}{c}{ Rp. 80.280} \\
\hline Total Biaya Langsung & Rp. 1.540 .498 \\
\hline
\end{tabular}

Biaya Tidak Langsung

Biaya tidak langsung terdiri dari biaya depresiasi yang meliputi depresiasi gedung dan alat, biaya operasional yang meliputi gaji pegawai unit penunjang dan biaya operasional lainnya seperti listrik, air, telephone, serta biaya pemeliharaan.

Total biaya tak langsung yang digunakan untuk satu pelayanan section caesarea adalah sebagai berikut. 
Tabel 5 Total Biaya Tidak Langsung Instalasi Kamar Operasi RSU X Surabaya

\begin{tabular}{ll}
\hline Biaya Tidak Langsung & Jumlah Biaya \\
\hline Biaya Depresiasai & $\mathrm{Rp} 13,677,265$ \\
Biaya operasional & $\mathrm{Rp} \mathrm{4,187,147,995}$ \\
Biaya Pemeliharaan & $\mathrm{Rp} 300.121 .162$ \\
\hline Total & $\mathrm{Rp} \mathrm{4.500.946.422}$ \\
\hline
\end{tabular}

\section{Pembebanan Biaya Tak Langsung}

Dari total biaya tak langsung yang didapatkan, kemudian dilakukan penghitungan pembebanan biaya tak langsung pada setiap aktivitas.
Tabel 6 menyajikan data penghitungan pembebanan biaya tak langsung. Total biaya tidak langsung pada aktivitas sekunder sebesar Rp 1,500,315,474. Total biaya tidak langsung pada aktivitas primer sebesara Rp 3,000,630,948.

\section{Unit Cost}

Unit cost satu layanan dapat dihitung berdasarkan biaya langsung dan rate biaya tak langsung pada proses layanan tersebut. Sehingga nilai unit cost untuk satu pelayanan operasi section caesarea adalah sebesar Rp $3,336,566$.

Tabel 6 Hasil Penghitungan Beban Biaya Tidak Langsung berdasarkan Kategori Aktivitas di Instalasi Kamar Operasi RSU X Surabaya

\begin{tabular}{|c|c|c|c|c|c|}
\hline Rincian Aktivitas & $\begin{array}{l}\text { Kategori } \\
\text { Aktivitas }\end{array}$ & $\begin{array}{l}\text { Waktu } \\
\text { (Menit) }\end{array}$ & $\begin{array}{l}\text { Jumlah } \\
\text { Pelayanan }\end{array}$ & $\begin{array}{l}\text { Jumlah } \\
\text { Cost } \\
\text { Driver } \\
\end{array}$ & $\begin{array}{l}\text { Jumlah BTL } \\
\text { (Rp) }\end{array}$ \\
\hline Pendaftaran Operasi & S 1 & 5 & 2,506 & 12,530 & $72,830,848$ \\
\hline $\begin{array}{l}\text { Pencatatan jadawal } \\
\text { operasi }\end{array}$ & S 2 & 5 & 2,506 & 12,530 & $72,830,848$ \\
\hline $\begin{array}{l}\text { Konfirmasi ke dokter } \\
\text { konsultan }\end{array}$ & S 3 & 10 & 2,506 & 25,060 & $145,661,697$ \\
\hline $\begin{array}{l}\text { Konfirmasi ke tim } \\
\text { bedah }\end{array}$ & S 4 & 10 & 2,506 & 25,060 & $145,661,697$ \\
\hline $\begin{array}{l}\text { Persiapan sarana dan } \\
\text { obat }\end{array}$ & S 5 & 15 & 2,506 & 37,590 & $218,492,545$ \\
\hline $\begin{array}{l}\text { Cek kelangkapan } \\
\text { adminstrasi }\end{array}$ & S 6 & 3 & 2,506 & 7,518 & $43,698,509$ \\
\hline $\begin{array}{l}\text { Menyiapkan kamar } \\
\text { operasi }\end{array}$ & S 7 & 10 & 2,506 & 25,060 & $145,661,697$ \\
\hline $\begin{array}{l}\text { Pencatatan kebutuhan } \\
\text { barang yang } \\
\text { digunakan }\end{array}$ & S 8 & 5 & 2,506 & 12,530 & $72,830,848$ \\
\hline $\begin{array}{l}\text { Kelengkapan } \\
\text { admistrasi }\end{array}$ & S 9 & 10 & 2,506 & 25,060 & $145,661,697$ \\
\hline $\begin{array}{l}\text { Pembersihan alat dan } \\
\text { ruangan }\end{array}$ & S 10 & 30 & 2,506 & 75,180 & $436,985,090$ \\
\hline Total BTL Aktivitas Sel & under & & & & $1,500,315,474$ \\
\hline Serah terima pasien & P 1 & 3 & 2,506 & 7,518 & $43,698,509$ \\
\hline $\begin{array}{l}\text { Pemberian tanda } \\
\text { daerah operasi }\end{array}$ & P 2 & 5 & 2,506 & 12,530 & $72,830,848$ \\
\hline $\begin{array}{l}\text { Mengirim ke kamar } \\
\text { operasi }\end{array}$ & P 3 & 3 & 2,506 & 7,518 & $43,698,509$ \\
\hline Preoperative time out & $\mathrm{P} 4$ & 5 & 2,506 & 12,530 & $72,830,848$ \\
\hline Anasthesia Procedur & P 5 & 5 & 2,506 & 12,530 & $72,830,848$ \\
\hline Positioning & P 6 & 5 & 2,506 & 12,530 & $72,830,848$ \\
\hline Operating procedure & $\mathrm{P} 7$ & 45 & 2,506 & 112,770 & $655,477,634$ \\
\hline $\begin{array}{l}\text { Durante Operatif time } \\
\text { out }\end{array}$ & P 8 & 10 & 2,506 & 25,060 & $145,661,697$ \\
\hline Penutupan luka & P 9 & 5 & 2,506 & 12,530 & $72,830,848$ \\
\hline Observasi post operasi & P 10 & 120 & 2,506 & 300,720 & $1,747,940,358$ \\
\hline \multicolumn{5}{|c|}{ Total BTL Aktivitas Primer } & $3,000,630,948$ \\
\hline
\end{tabular}




\section{PEMBAHASAN}

Metode yang digunakan dalam analisis biaya adalah metode Activity Based Costing (ABC). $A B C$ pada dasarnya merupakan metode penentuan harga pokok produk yang ditujukan untuk menyajikan informasi harga pokok secara cermat dengan cara mengukur konsumsi sumber daya dalam setiap aktivitas yang digunakan untuk menghasilkan produk. $A B C$ menitik beratkan pada penentuan harga pokok produk pada semua fase pembuatan produk. $A B C$ dilandasi oleh keyakinan dasar bahwa biaya ada penyebabnya, dan penyebab biaya dapat dikelola. Penyebab biaya adalah aktivitas, dan melalui penyediaan informasi lengkap tentang aktivitas, maka akan dapat dilakukan pengelolaan terhadap aktivitas secara efektif.

Menurut Mulyadi, 2007, Activity Based Costing bukan sekedar costing method atau metode penentuan harga satuan produk untuk kepentingan penghitungan biaya investasi yang akan disajikan dalam neraca, namun lebih dari itu. Activity Based Costing merupakan sistem informasi biaya yang mampu menyediakan informasi biaya untuk memungkinkan manajemen melakukan pengelolaan berbasis aktivitas (activity based management).

Activity based costing ( $A B C)$ adalah pendekatan penentuan biaya produk yang membebankan biaya kepada produk atau jasa berdasarkan konsumsi sumber daya yang disebabkan karena aktivitas. Dasar pemikiran pendekatan penentuan biaya ini adalah bahwa untuk menghasilkan produk atau jasa perusahaan perlu dilakukan suatu aktivitas dimana aktivitas yang dibutuhkan tersebut menggunakan sumber daya yang menyebabkan timbulnya biaya. Aktivitas mengendalikan biaya, dimana biaya dikendalikan oleh produk dan produk dikendalikan oleh pelanggan. Asumsi ini secara radiakal berbeda dengan sistem penetapan biaya produksi konvensional yang berlandaskan asumsi bahwa produk mengendalikan biaya secara langsung (Gaspersz, 2006).

Menurut Hansen dan Mowen (2004) perbedaan sistem alokasi dua tahap antara $A B C$ dengan tradisional adalah:
1. Pada sistem tradisional, tahap pertama biaya overhead dialokasikan kepada setiap departemen, sleanjutnya pada tahap kedua dialokasikan kepada setiap produk.

2. Pada sistem $A B C$, tahap pertama biaya overhead dialokasikan kepada setiap aktivitas, selanjutnya tahap kedua dialokasikan kepada setiap produk.

\section{SIMPULAN DAN SARAN}

Penghitungan unit cost jasa pelayanan operasi section caesarea di lakukan dengan menggunakan activity based costing. Unit cost jasa pelayanan operasi sectio caesarea adalah sebesar Rp 3,336,566,- (tiga juta tiga ratus tiga puluh enam ribu lima ratus enam puluh enam rupiah).

\section{DAFTAR PUSTAKA}

Gaspersz, Vincent. 2006. Continuous Cost Reduction Through Lean-Sigma Approach. Jakarta : PT Gramedia Pustaka Utama,

Hansen dan Mowen. 2004. Manajemen Biaya Akuntansi dan Pengendalian Edisi Kedelapan. Jakarta: Salemba Empat

Mulyadi. 2007. Sistem Perencanaan dan Pengendalian Manajemen. Jakarta: Salemba Empat

Ratmaya, Ketut Anom. 2012. Penghitungan Biaya Kamar Operasi Menggunakan Activity Based Costing di Rumah Sakit Umum Puri Raharja. Tesis. Depok : Universitas Indonesia 
JURNAL ILMIAH KESEHATAN MEDIAHUSADA ｜ＶOLUME 06/NOMOR 02/OKTOBER 2017 